\title{
Coastal National Elevation Database
}

\section{Introduction}

The Coastal National Elevation Database (CoNED) Applications Project develops enhanced topographic (land elevation) and bathymetric (water depth) datasets that serve as valuable resources for coastal hazards research (Danielson and others, 2016; Thatcher and others, 2016). These datasets are used widely for mapping inundation zones from riverine flood events, hurricanes, and sea-level rise and for other Earth science applications, such as sediment transport, erosion, and storm impact models.

CoNED is a U.S. Geological Survey (USGS) Coastal-Marine Hazards and Resources Program (formerly Coastal and Marine Geology Program) activity centered at the USGS Earth Resources Observation and Science Center and distributed at other USGS Science Centers. As part of the vision for a 3D Nation, the CoNED Project is working collaboratively with the USGS National Geospatial Program, the National Oceanic and Atmospheric Administration, and the U.S. Army Corps of Engineers through the Interagency Working Group on Ocean and Coastal Mapping to build integrated elevation models in the coastal zone by assimilating the land surface topography with littoral zone and continental shelf bathymetry. Several nongovernmental organizations and Federal agencies, including the Department of the Interior Pacific Islands Climate Adaptation Science Center, the National Park Service, the Nature Conservancy, the Louisiana Coastal Protection and Restoration Authority, and numerous academic institutions, partner to make CoNED a success.

\section{Goals and Benefits}

The primary goal of CoNED is to provide seamless, cross-shore integrated topobathymetric digital elevation models (TBDEMs) to support coastal and marine spatial planning. CoNED also enhances the USGS 3D Elevation Program (3DEP) by providing coastal communities with integrated elevation information for coastal zone decision support applications on the U.S. ocean coasts and the Great Lakes.

CoNED fulfills a fundamental need of the USGS Land Resources (formerly Climate and Land Use Change) Science Strategy and responds directly to USGS science goals by

- Improving the understanding and prediction of coastal response to sea-level rise, climate change, and human development;

- Developing TBDEMs at select focus regions for scientific investigations and applications for land change science research to support coastal and marine spatial planning; and

- Providing seamless TBDEMs extending from onshore coastal areas through the U.S. Exclusive Economic Zone out to a 3-nautical mile limit offshsore.

The CoNED methodology improves and implements technology and techniques for the integration of coastal topobathymetric mapping data, such as with land water masking algorithms and complex geospatial multitemporal frameworks (Danielson and others, 2016).

\section{CoNED TBDEMs}

CoNED TBDEM development is focused in select regions around the U.S. coast, such as the Northern Gulf of Mexico, the eastern seaboard from New England to North Carolina, California, the Pacific Northwest, the North Slope of Alaska, and select western Pacific islands and atolls. CoNED TBDEMs are constructed from multisource topographic and bathymetric data that are aligned vertically and horizontally to a common reference system.

The first high-resolution CoNED TBDEM was produced in 2012 for Mobile Bay, Alabama, the fourth largest estuary in the United States (Gesch, 2013). Highly detailed TBDEMs continue to be developed for coastal regions including Chesapeake Bay,

Delaware, New England, New Jersey, the Northern Gulf of Mexico, Central California, Southern California, Puget Sound, and Majuro Atoll, Republic of the Marshall Islands.
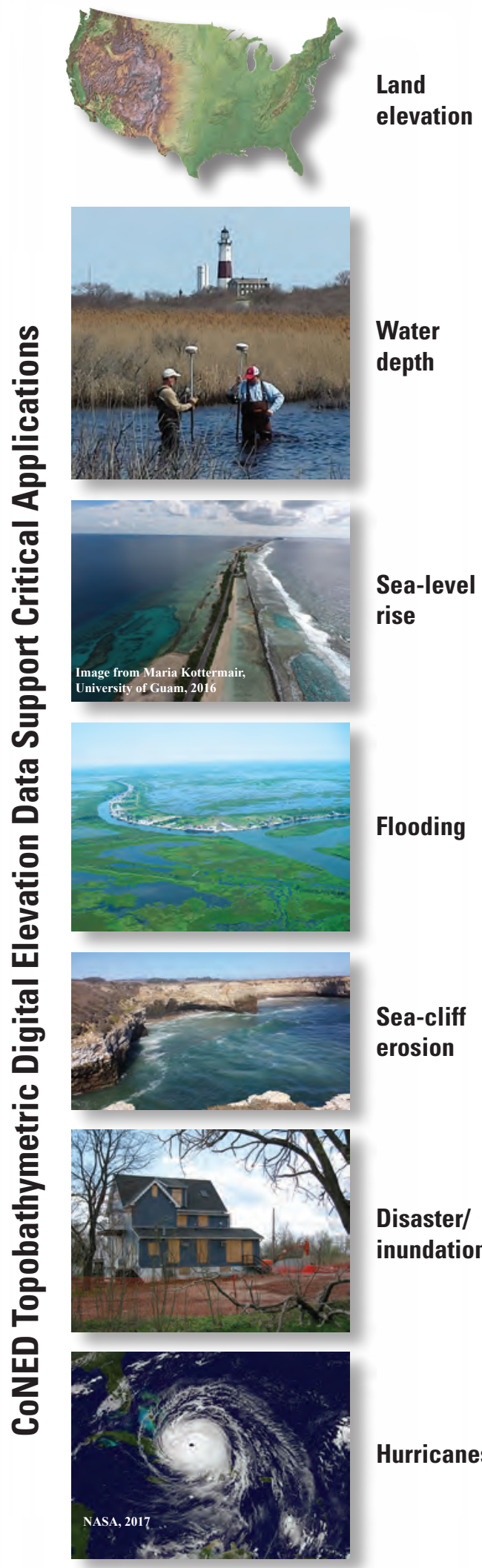

\section{Land \\ elevation \\ Sea-cliff erosion \\ Disaster/ inundation \\ Flooding

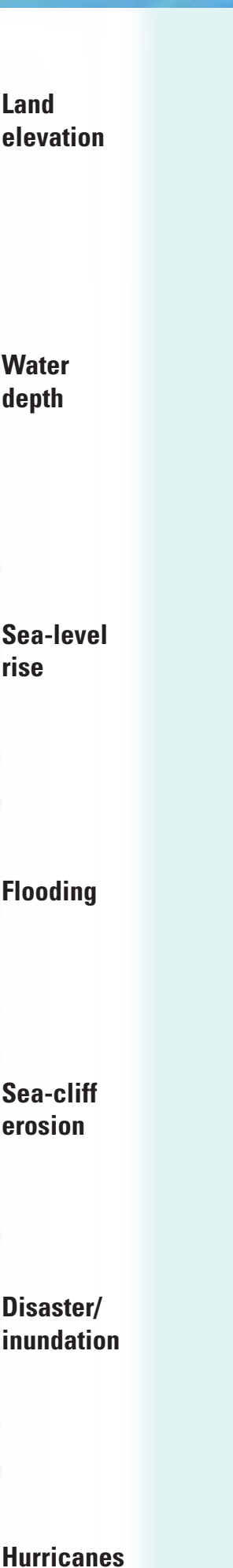

Hurricanes

Landscape change and vulnerability 


\section{CoNED Scientific Research}

The onshore-offshore cross ecosystem coverage of CoNED TBDEMs supports scientific research assessing the effects of various changes to vulnerable coastal regions subject to powerful storms, including hurricanes on the east and gulf coasts and extratropical cyclones on the west coast.

In support of hazard vulnerability and ecosystem resilience research, complex configurations of coastal emergent wetlands and open water were delineated by CoNED scientists to provide wetland extent information that is valuable for storm surge and sediment transport models, shoreline change detection analysis, and wetland classification maps. The accuracy of coastal land elevation maps directly affects the reliability and usefulness of elevation based sea-level rise vulnerability and inundation assessments (Gesch, 2013). Therefore, detailed and comprehensive CoNED TBDEMs are a key variable in understanding the likely effects of natural hazards.

Sea cliff and bluff erosion is a serious hazard for coastal infrastructure and residential dwellings. The availability of CoNED TBDEMs and high-resolution 3D point clouds from light detection and ranging (lidar) has led to advancements in quantifying volumetric change in areas vulnerable to sea cliff and bluff failure (Palaseanu-Lovejoy and others, 2016). Coastal change monitoring through automatically extracted cliff and bluff metric profiles has important benefits to local communities for analyzing economic resource planning and hazard mitigation.

The lack of Pacific Islands TBDEMs led CoNED researchers to use advanced remote sensing technologies to develop land surface topography from Structure-from-Motion point clouds derived from unmanned aerial system photography and satellite-derived bathymetry from Landsat and WorldView imagery (Poppenga and others, 2018). Lidar data, acquired along the north coast of Alaska from 2009 to 2012 , were used to produce detailed land elevations to establish a modern shoreline position for shoreline change and coastal hazards assessments and evaluating landscape patterns.

\section{References}

Danielson, J.J., Poppenga, S.K., Brock, J.C., Evans, G.A., Tyler, D.J., Gesch, D.B., Thatcher, C.A., and Barras, J.A., 2016, Topobathymetric elevation model development using a new methodology — Coastal National Elevation Database: Journal of Coastal Research, no. SI 76, p. 74-88. [Also available at https://doi.org/10.2112/ SI76-008.]
Gesch, D.B., 2013, Consideration of vertical uncertainty in elevation-based sea-level rise assessments-Mobile Bay, Alabama case study: Journal of Coastal Research, no. SI 63, p. 197-210. [Also available at https:// doi.org/10.2112/SI63-016.1.]

National Aeronautical and Space Administration [NASA], 2017, Irma (Atlantic Ocean): NASA web page, accessed October 2017 at https://www.nasa.gov/feature/goddard/2017/irma-atlantic-ocean.

Palaseanu-Lovejoy, M., Danielson, J., Thatcher, C., Foxgrover, A., Barnard, P., Brock, J., and Young, A., 2016, Automatic delineation of seacliff limits using lidarderived high-resolution DEMs in southern California: Journal of Coastal Research, no. SI 76, p. 162-173. [Also available at https://doi.org/10.2112/SI76-014.]

Poppenga, S.K., Palaseanu-Lovejoy, M., Gesch, D.B., Danielson, J.J., and Tyler, D.J., 2018, Evaluating the potential for near-shore bathymetry on the Majuro Atoll, Republic of the Marshall Islands, using Landsat 8 and WorldView-3 imagery: U.S. Geological Survey Scientific Investigations Report 2018-5024, 22 p. [Also available at https://doi.org/10.3133/sir20185024.]

Thatcher, C.A., Brock, J.C., Danielson, J.J., Poppenga, S.K., Gesch, D.B., PalaseanuLovejoy, M.E., Barras, J.A., Evans, G.A., and Gibbs, A.E., 2016, Creating a Coastal National Elevation Database (CoNED) for science and conservation applications: Journal of Coastal Research, no. SI 76, p. 64-73. [Also available at https://doi. org/10.2112/SI76-007.]

\section{For More Information}

CoNED information can be found at https://topotools.cr.usgs.gov/coned/ or by contacting Jeffrey J. Danielson at daniels@usgs.gov.

Photographs and images from the U.S. Geological Survey, unless otherwise credited.

Publishing support provided by the Rolla Publishing Service Center.

ISSN 2327-6916 (print)

ISSN 2327-6932 (online)

https://doi.org/10.3133/fs20183037

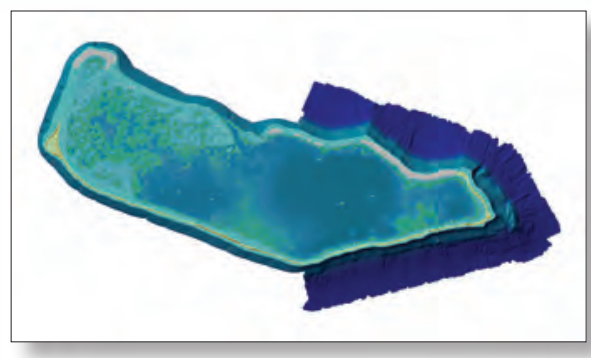

Majuro Atoll, Republic of the Marshall Islands, TBDEM

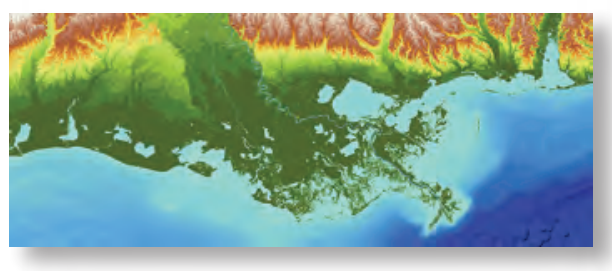

\section{Northern Gulf of Mexico, including Mobile Bay, Alabama, TBDEM}

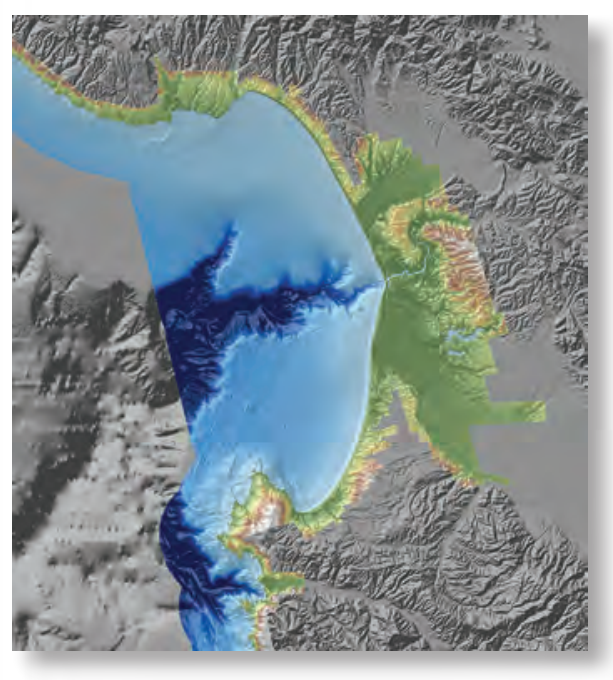

Monterey Bay, central California, TBDEM

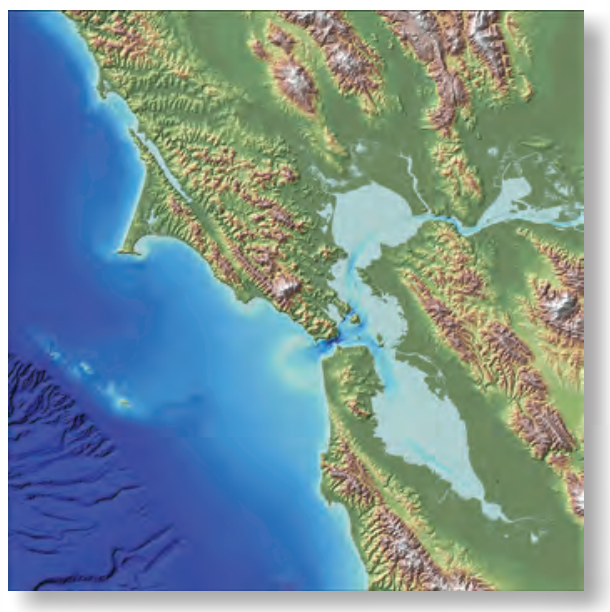

San Francisco Bay area, California, TBDEM 